\title{
ARDUINO SEBAGAI PENGONTROL SMART VIVARIUM DENGAN NOTIFIKASI MENGGUNAKAN ANDROID
}

\author{
Sepsa Nur Rahman ${ }^{1)}$,Lika Jafnihirda ${ }^{2)}$,Teri Ade Putra ${ }^{3)}$ \\ ${ }^{1}$ Fakultas Ilmu Komputer, Universitas Putra Indonesia "YPTK" Padang \\ email : sepsanurrahman@yahoo.com \\ ${ }^{2}$ Fakultas Keguruan Ilmu Pendidikan, Universitas Putra Indonesia "YPTK” Padang \\ email : likajafnihirda@gmail.com \\ ${ }^{3}$ Fakultas Ilmu Komputer, Universitas Putra Indonesia "YPTK" Padang \\ email : teriputra2@gmail.com
}

\begin{abstract}
Abstrak
Peranan proses melepaskan ketegangan dan mengembalikan keseimbangan baik pikiran maupun tubuh. Teknik relaksasi visualisasi sangat penting dalam mengelola stres. Relaksasi mungkin menjadi salah satu faktor yang paling penting dalam menjaga kesehatan tubuh dan pikiran. Teknik relaksasi dapat menguntungkan baik kesehatan psikologis dan fisik manusia. Arduino adalah pengendali mikro single-board yang bersifat open-source, diturunkan dari Wiring platform, dirancang untuk memudahkan penggunaan elektronik dalam berbagai bidang. Arduino memiliki prosesor AtmelAVR dan memiliki bahasa pemrograman sendiri. Dalam penelitian ini penulis merancang dan membuat sebuah alat system pengontrolan smart vivarium menggunakan android berbasis Arduino. Komponen utama yang digunakan dalam penelitian ini adalah Smartphone digunakan sebagai input untuk memilih beberapa pilihan, Arduino Mega2560 digunakan sebagai pengontrol komponen input dan output, Bluetooth Recieved HC-05 sebagai transisi data dari Smartphone ke Arduino Mega2560 , lampu LED digunakan sebagai komponen output untuk penerangan vivarium, Mist Machine digunakan sebagai penghasil uap buatan, Waterpump alat untuk penyiraman tanaman, DFPlayer Mini MP3 Module dan Loudspeaker berfungsi sebagai komponen output yang akan mengeluarkan suara berupa lagu relaksasi. Pembuatan alat ini dapat meningkatkan ketertarikan dan pengetahuan bagi pencinta tanaman khususnya vivarium dan akan menjadi lebih efektif dalam perawatannya.
\end{abstract}

Keyword: Arduino Mega2560, Waterpump, Mist Machine, DFPlayer Mini Mp3 Module, Bluetooth

\section{PENDAHULUAN}

Teknik relaksasi visualisasi sangat penting dalam mengelola stres. Relaksasi mungkin menjadi salah satu faktor yang paling penting dalam menjaga kesehatan tubuh dan pikiran. Teknik relaksasi dapat menguntungkan baik kesehatan psikologis dan fisik manusia[1]. Dengan berkembangnya teknologi yang ada saat ini, manusia mulai menciptakan inovasi yang membantu memudahkan pekerjaan sehari-hari yang dapat bekerja secara otomatis dan memiliki ketelitian tinggi dengan bantuan microcontroller.

Terlebih lagi untuk memaksimalkan dan menghemat waktu dalam menjalankan kegiatan. Demikian halnya dalam dunia hobi maupun kesehatan. Pada saat ini banyak orang hobi pecinta tanaman yang mengkreasikan hobinya dengan sangat unik salah satunya memiliki vivarium di dalam rumahnya. Istilah vivarium sendiri berasal dari bahasa latin "Vivaria" yang berarti "Place of life" tempat kehidupan dan "Arium" yang berarti sebuah wadah atau tempat yang hampir semuanya 
tertutup[2]. Dalam hal ini, istilah vivarium bersifat umum atau generic karena segala macam bentuk kehidupan

\section{METODOLOGI PENELITIAN}

\section{KERANGKA PENELITIAN}

Kerangka penelitian merupakan langkah-langkah yang akan dilakukan dalam rangka menyelesaikan masalah yang akan dibahas[3]. Adapun kerangka kerja dari penilitian ini dapat disajikan pada Gambar 1 dibawah ini.

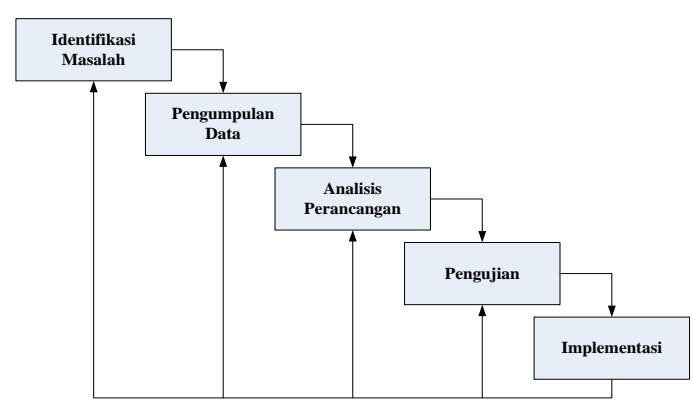

Gambar 1. Kerangka Penelitian

\section{URAIAN KERANGKA KERJA PENELITIAN}

Adapun tahap-tahap yang akan dilakukan dalam penelitian ini adalah sebagai berikut:

\section{IDENTIFIKASI MASALAH}

Identifikasi masalah merupakan tahap awal dalam perancangan dan pengembangan sistem yang akan dirancang, karena pada tahap inilah akan diukur dan dievaluasi kinerja sistem yang dirancang. Identifikasi terhadap masalahmasalah yang ada dan langkah-langkah untuk kebutuhan perancangan yang diharapkan[5].

Dalam identifikasi masalah, penulis terlebih dahulu harus mengetahui dan memahami sistem.Untuk menganalisa sistem diperlukan data untuk di analisa. Data yang diperlukan atau ekosistem yang ditempatkan pada sebuah wadah tertutup bisa disebut vivarium.

adalah hal-hal yang berkenan dengan defenisi data.[4]

\section{PENGUMPULAN DATA}

Untuk mendapatkan hasil yang optimal, maka penulis menggunakan beberapa metode penelitian dalam pengumpulan data yaitu:

1. Penelitian Lapangan

Metode ini dilakukan untuk menguji konsep-konsep yang ada dengan menggunakan peralatan yang dipakai dan sesuai. Adapun objek yang diuji spesifikasi hardware dan software yang digunakan dalam penulisan ini adalah sebagai berikut :

Tabel 1. Hardware dan Software yang

digunakan

\begin{tabular}{ll}
\hline HARDWARE & SOFTWARE \\
\hline a. Satu Unit & a. Sistem Operasi \\
Laptop & Windows 7 \\
TOSHIBA & Pro-64 bit \\
b. Memory 2048 & dilengkapi \\
Mbyte RAM & Microsoft \\
c. Hard Disk 500 & Office 2010 \\
Gbyte & b. Bahasa \\
d. Mouse Standar & pemrograman \\
Serial & Arduino \\
e. Printer Canon & c. Fritzing \\
PIXMA & d. App Inventor \\
IP2770 & \\
f. Kabel & \\
Downloader & \\
g. Multitester & \\
\hline
\end{tabular}

2. Penelitian Perpustakaan

Pengumpulan data-data sekunder dengan membaca buku-buku, jurnal dan referensi-referensi lainnya menyangkut masalah yang berhubungan dengan pembahasan 
dalam skripsi. Dalam metode ini dilakukan kajian literature yang bertujuan untuk memperoleh solusisolusi pemecahan masalah apa saja yang dapat digunakan untuk menyelesaikan masalah yang di hadapi dalam perancangan sistem dan alat.

\section{ANALISA PERANCANGAN}

Berdasarkan identifikasi masalah di atas, peneliti melakukan analisa dan perancangan system terlebih dahulu. Hal ini bertujuan agar pemecahan masalah dapat menghasilkan sebuah solusi yang baru. System yang digunakan adalah sebagai berikut:

a. Data Flow Diagram

Data Dlow Diagram atau yang disingkat $D F D$ merupakan suatu diagram yang menggambarkan alir data dalam suatu entitas ke sistem atau sistementitas. DFD juga dapat diartikan sebagai teknik grafis yang menggambarkan alir data dan transformasi yang digunakan sebagai perjalanan data dari input menuju output.

b. Flowchart Program

Flowchart program adalah keterangan yang lebih rinci tentang bagaimana setiap langkah program atau prosedur sesungguhnya dilaksanakan. Flowchart ini menunjukkan setiap langkah program atau prosedur dalam urutan yang tepat saat terjadi. Programmer menggunakan Flowchart program untuk menggambarkan urutan instruksi dari program komputer. Simbol-simbol Flowchart yang biasanya dipakai adalah simbolsimbol Flowchart standar yang di keluarkan ANSI dan ISO.

\section{Arduino}

Arduino adalah sebuah sebuah kit atau papan elektronik yang dilengkapi dengan software open source yang menggunakan keluarga mikrokontroler ATMega dan berfungsi sebagai pengendali mikro single-board yang dirancang untuk memudahkan penggunaan elektronik dalam berbagai bidang yang dirilis oleh Atmel. Dimana Hardwarenya memiliki prosesor Atmel AVR dan softwarenya memiliki bahasa pemrograman sendiri [6]. Arduino Merupakan papan elektronik berbasis mikrokontroller ATMega yang memenuhi sistem minimum mikrokontroller agar dapat bekerja secara mandiri (standalone controller) [7]. Berikut gambar Arduino pada gambar 2.

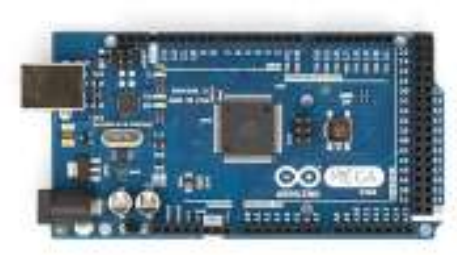

Gambar 2. Modul Arduino Mega 2560

\section{DFPlayer Mini}

DFPlayer mini adalah modul mp3 yang outputnya sederhana, dapat langsung diaplikasikan pada pengeras suara speaker. DFPlayer mini dapat digunakan dengan cara berdiri tunggal menggunakan baterai, speaker, dan push button, juga dapat digunakan pada Arduino Uno ataupun dengan perangkat lain yang memiliki kemampuan receiver/transmitter [8]. DFPlayer Mini adalah sebuah modul micro SD dimana modul tersebut dapat mengases dan menyimpan data pada micro SD.. [9]. Modul DFPLayer Mini adalah 
sebuah modul MP3 serial yang menyiakan kesempurnaan integrasi MP3, WMV hardware decoding. Sedangkan softwarenya mendukung driver TF card, mendukung sistem file FAT16, FAT32. Melalui perintah-perintah serial sederhana untuk menentukan memutar musik, serta bagaimana cara memutar musik dan fungsi lainnya, tidak melalui operasi yang rumit, mudah digunakan, stabil dan dapat diandalkan adalah fiturfitur yang paling penting dari modul ini. Modul ini dapat digunakan sebagai modul yang berdiri sendiri dengan menggunakan baterai (Ratna et al., 2019). Untuk memperjelas keterangan diatas gambar DFPlayer mini dapat dilihat dibawah ini gambar pada gambar 3 .

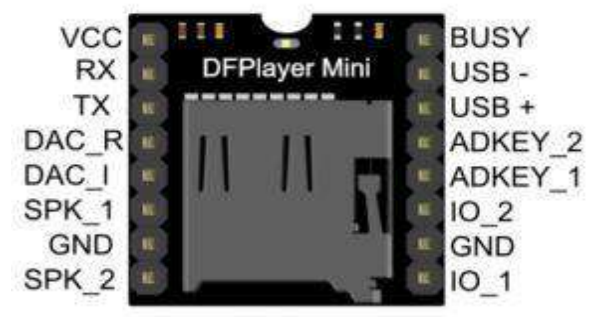

Gambar 3. DFPlayer Mini

\section{Mist Machine}

Mist Maker/ Mesin Kabut adalah alat yang dapat merubah air biasa menjadi awan kabut seperti dinginnya es yang biasa terlihat pada bidang es. Dengan proses ultrasonic automizaton, air diubah menjadi kabut tetapi tidak menguap ke atas. Juga dapat digunakan sebagai "aroma therapy" jika anda memasukna aroma terapi didalam airnya. Memiliki lampu warna-warni yang menyala secara bergantian,[10]

Mist Maker/Mesi kabut adalah alat yang dapat merubah air biasa menjadi awan kabut seperti dingi nya es yang biasa terlihat pada bidang es. Dengan proses ultrasonic automizaton. Air diubah menjadi kabut tetapi tidak menguap ke atas. Juga dapat diguaka sebagai aroma terapi didalam airnya.
Memiliki lampu berwarna warni yang menyala bergantian. (Utara et al., 2017)

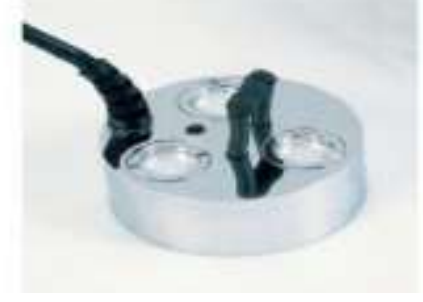

Gambar 4. Mist Machine

\section{Waterpump}

Water pump atau pompa air adalah alat elektronik yang berfungsi sebagai penggerak dengan kegunaan untuk menyedot air dan mengeluarkannya kembali, pompa juga memiliki cara kerja dalam beberapa mekanisme :

1. Mekanisme awal

Cara kerjanya adalah dengan dibagian fungsi dynamo pada mesin pompa aquarium. Dynamo tersebut akan bergerak dengan adanya fasilitas daya listrik pada pompa. Fungsinya untuk menarik air agar masuk pada mesin filter, dan air hanya akan berputar-putar di sana.

2. Mekanisme Pertengahan

Setelah dynamo bekerja, maka akan terjadi stabilitas peputaran air secara berkala. Maka pada saat itu, proses penyaringan air kotor pun terjadi. Proses penyaringan ini memang sangat penting agar air dalam aquarium tetap bersih.

\section{Mekanisme Akhir}

Nah yang terakhir ini setelah air disaring, maka hasil airnya akan kembali masuk ke dalam aquarium. Jadi air dalam aquarium tersebut tetap dalam kondisi bersih dan bebas dari bakteri. 


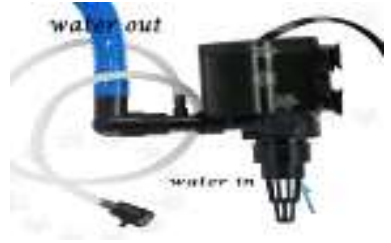

Gambar 5. Waterpump

\section{Bluetooth}

Modul Bluetooth HC-05 adalah converter komunikasiserial level TTL (UART)kedalam bentuk komunikasi wirelessyaitu bluetooth. Modul Bluetooth HC-05 dan HC-06 dapatdikontrol mode kerjanya dengan menggunakan standar ATCommand.Level tegangan dari komunikasi serial dariBluetooth HC-05 adalah 0 dan 3.3 volt High $=3.3$ Volt danLow $=0$ Volt. Ini berbeda dengan level tegangan darikomunikasi serial di mikrokontroler.

Ada dua jenis bluetooth ke modul serial dengan ganjil dan genap. Bluetooth seri bernomor ganjil sebagai HC-05 atau HC-03 adalah versi perbaikan dari Bluetooth untuk Serial Modul HC-06 atau HC-04. Bluetooth ke serial modul HC-05 dapat ditetapkan sebagai master atau slave perangkat seperti HC-06 modul yang hanya bisa digunakan sebagai Slave. Bluetooth konfigurasi modul pin Serial HC-05 ditunjukkan pada Gambar 6 (Zainuri et al., 2015).

Modul Bluetooth HC-05 adalah converter komunikasi serial level TTL (UART) kedalam bentuk komunikasi wireless yaitu bluetooth. Modul Bluetooth HC-05 dan HC-06 dapat dikontrol mode kerjanya dengan menggunakan standar ATCommand. Level tegangan dari komunikasi serial dari Bluetooth HC-05 adalah 0 dan 3.3 volt High $=3.3$ Volt dan Low $=0$ Volt. Ini berbeda dengan level tegangan dari komunikasi serial di mikrokontroler. Jadi untuk mengirim data dari mikrokontroler ke Modul Bluetooth lewat komunikasi serial diperlukan voltage devider yaitu
R1 dan R2 sehingga sesuai dengan level tegangan dari komunikasi serial di Modul Bluetooth. Sedangkan untuk Transmit data dari modul Bluetooth ke mikrokontroler tidak lagi memerlukan voltage devider, karena level 3.3 Volt dari Modul Bluetooth sudah dianggap Level High oleh mikrokontroler sedangkan Level Low dari Modul bluetooth tetap di angka 0 Volt (Rumimper et al., 2016)

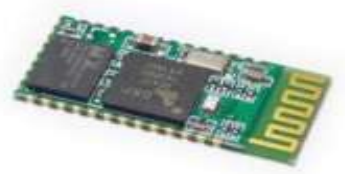

Gambar 6. Bluetooth HC-05

Android

Android Android adalah sistem operasi berbasis Linux yang dirancang untuk perangkat bergerak layar sentuh seperti telepon pintar dan komputer tablet. Android awalnya dikembangkan oleh Android, Inc dengan dukungan finansial Google, yang kemudian membelinya pada tahun 2005.

Sejarah Android Android adalah sistem operasi yang berbasis Linux untuk telepon seluler seperti telepon pintar dan komputer tablet. Android menyediakan platform terbuka bagi para pengembang untuk menciptakan aplikasi mereka sendiri untuk digunakan oleh bermacam peranti bergerak. Awalnya, Google Inc. membeli Android Inc., pendatang baru yang membuat peranti lunak untuk ponsel. Kemudian untuk mengembangkan Android, dibentuklah Open Handset Alliance, konsorsium dari 34 perusahaan peranti keras, peranti lunak, dan telekomunikasi, termasuk Google, HTC, Intel, Motorola, Qualcomm, TMobile, dan Nvidia. Pada saat perilisan perdana Android, 5 November 2007, Android bersama Open Handset Alliance menyatakan mendukung pengembangan standar terbuka pada perangkat seluler. Di lain 
pihak, Google merilis kode \pm kode Android di bawah lisensi Apache, sebuah lisensi perangkat lunak dan standar terbuka perangkat seluler.

\section{PENGUJIAN SISTEM}

Dalam tahapan ini penulis akan menganalisa kinerja dari sistem apakah sudah berjalan dengan baik dan sesuai yang diharapkan sebelum sistem diimplementasikan. Sebelum melukukan implementasi penulis melakukan pengujian sistem terlebih dahulu untuk memastikan software dan hardware dapat bekerja dengan baik.

\section{IMPLEMENTASI}

Implementasi merupakan tahap melakukan penerapan sistem atau alat yang dibuat sehingga siap untuk dioperasikan. Pada tahap ini alat atau software dan hardware sudah selesai.

\section{EVALUASI}

Evaluasi juga dibutuhkan agar alat yang dibuat sesuai dengan kebutuhan agar dapat digunakan oleh pengguna. Tujuan dari evaluasi yaitu untuk melihat seberapa tepat alat yang dibuat sehingga sesuai dengan kebutuhan dan mengidentifikasi masalah yang terjadi pada sistem.

\section{HASIL DAN PEMBAHASAN}

Secara umum bentuk dari display (tampilan)sistem ini terdiri atas sistem mekanik dan rangkaian elektronika. Gerakan dari sistem mekanik akan ditentukan oleh gerakan simulasi yang digunakan, sedangkan rangkaian elektronika berfungsi untuk memberikan data berupa sinyal yang akan diproses oleh mikrokontroler sesuai logika program yang dirancang.

\section{CONTEXT DIAGRAM}

Context Diagram adalah pendefenisian terhadap sistem yang akan dirancang yang bersifat menyeluruh. Context Diagram digunakan untuk memudahkan proses penganalisaan terhadap sistem yang dirancang secara keseluruhan. Dalam hal ini context diagram berfungsi sebagai media yang terdiri dari suatu proses dan beberapa buah eksternal entity.

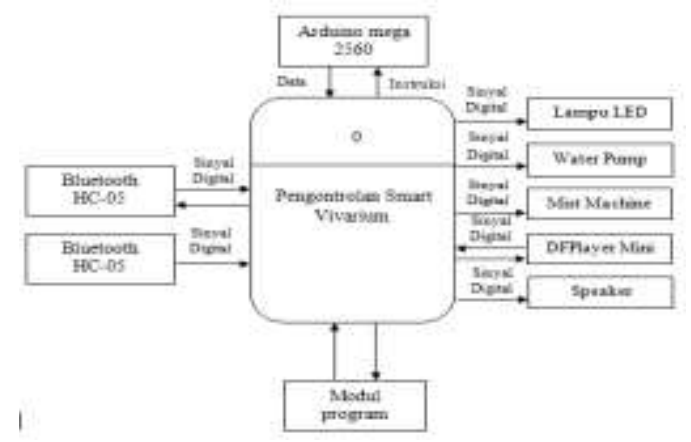

Gambar 7. Context Diagram

\section{DATA FLOW DIAGRAM}

Data Flow Diagram adalah gambaran yang lebih rinci dari alat yang dirancang. Data Flow Diagram ini diuraikan berdasarkan Context Diagram yang telah dijabarkan sebelumnya.

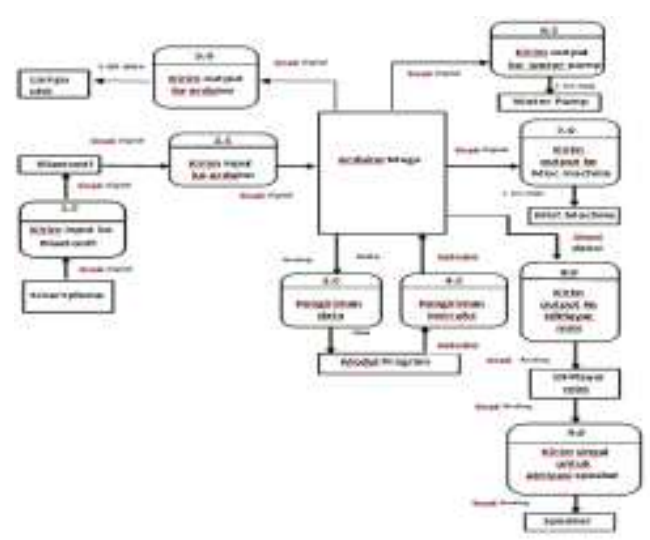

Gambar 8. Data Flow Diagram (DFD)

BLOK DIAGRAM 
Dari rancangan fisik alat maka dapat digambarkan blok diagram peralatan sebagai berikut:

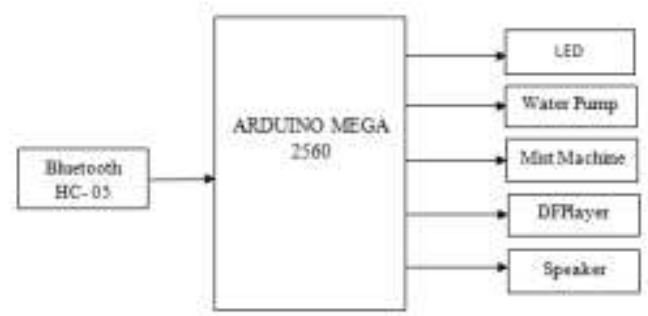

Gambar 9. Blok Diagram

\section{FLOWCHART}

Modul program dirancang dengan struktur dan kualitas yang baik serta mudah dimengerti, maka sebelum pembuatan listing program perlu diawali dengan penentuan logika program. Logika dasar gambaran program pada penulisan ini adalah dengan menggunakan flowchart.

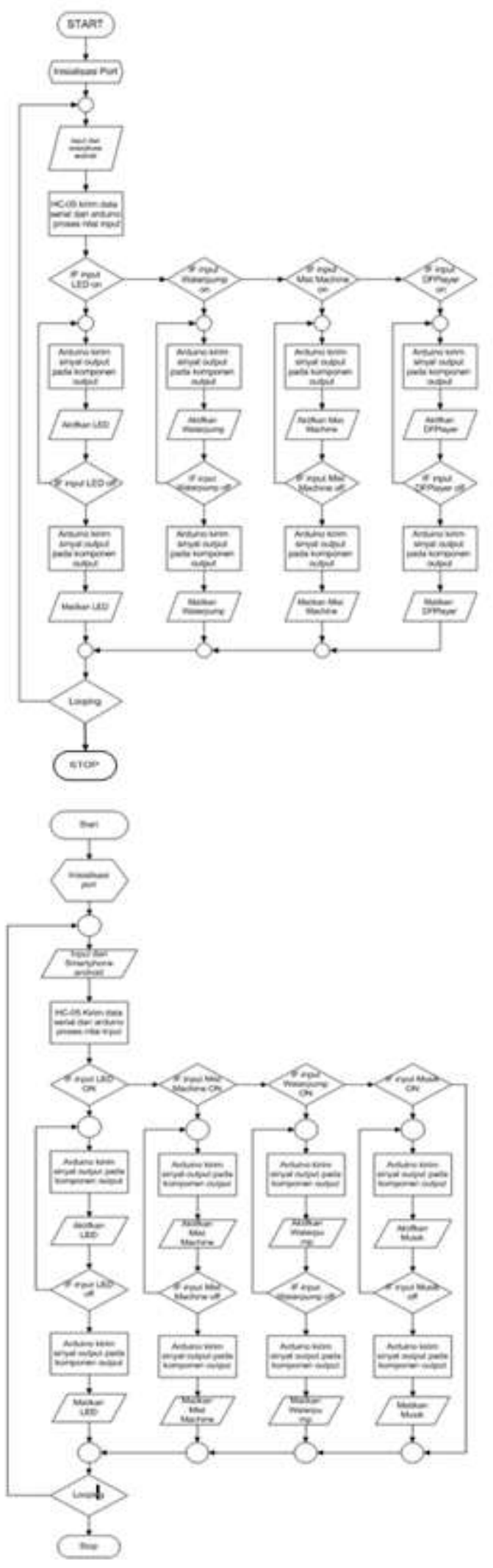




\section{PENGUJIAN SISTEM}

Pengujian sistem ini dapat dilakukan mulai dari pengujian alat permodul sampai pengujian alat secara keseluruhan. Langkah-langkah dalam pengujian alat tersebut adalah sebagai berikut :

\section{PENGUJIAN KOMPONEN}

\section{BLUETOOTH}

Pengujian komponen bluetooth berfungsi untuk mengaktifkan sinyal bluetoothditandai dengan indikator LED yang aktifpada modulbluetoothdengan berkedip lebih pelan dari sebelumnya sehingga diketahui modul bluetooth telah terkoneksi dengan bluetooth smartphone Android.

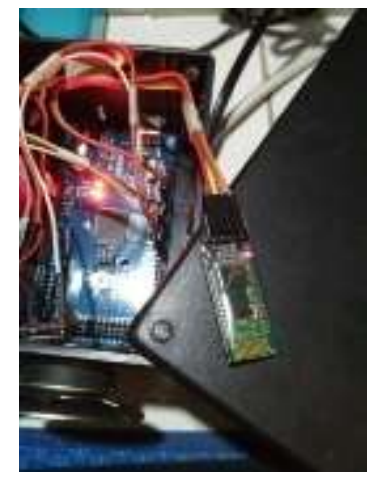

Gambar 10. Pengujian Komponen Bluetooth

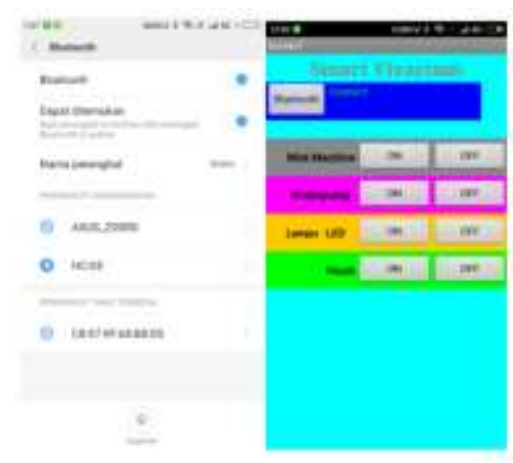

Gambar 11. Tampilan Koneksi Bluetooth Pada Smartphone

\section{PENGUJIAN RANGKAIAN}

\section{KESELURUHAN}

Seluruh sistem kendali dipegang sepenuhnya oleh mikrokontroler Arduino berdasarkan program yang tersimpan dalam chip mikrokontroler Arduino. Pengujian dari sistem ini dapat dilakukan dengan beberapa langkah berikut:

1. Pasang kabel power supply untuk men-supply tegangan rangkaian sehingga alat berada pada kondisi stand-by.

2. Buka program aplikasi vivarium pada smartphone dengan keadaan Bluetooth smartphone diaktifkan.

3. Kemudian pilih connect untuk menghubungkan Bluetooth smartphone Android denganmodul bluetooth HC-05 yang ada pada modul rangkaian.

4. Setelah bluetooth terkoneksi, maka proses pengontrolan dapat dilakukan dengan memilih beberapa pilihan yang ada pada aplikasi untuk memilih alat apa yang akan di aktifkan .

5. Untuk pilihan lain pada aplikasi yaitu terdapat pilihan OFF, OFF berfungsi untuk mengembalikan alat pada keadaan stand-by.

\section{SIMPULAN}

Berdasarkan penjelasan yang tertera pada bab-bab sebelumnya, maka dapat diambil kesimpulan sebagai berikut : Proses penginstruksian dan komunikasi antara Arduino Mega 2560, Bluetooth HC-05 dan Smartphone berjalan dengan baik, Dengan pembuatan aplikasi menggunakan rancangan pada Tool APP Inventor alat berjalan dengan baik dan mudah diaplikasikan, DFPlayer Mini berfungsi dengan baik sebagai output dengan cara memutar file suara di kartu memori pada Loudspeaker yang berisi lagu relaksasi, Relay bekerja dengan baik untuk mengontrol output 
Jurnal KomtekInfo , Vol.7 No.4 Tahun 2020

e-ISSN : 2502-8758 || p-ISSN : 2356-0010 DOI : $\underline{\text { 10.35134/komtekinfo.v7i4 }}$

Page : 260-269

Lampu LED, Waterpump, Mist Machine, Mist Machine bekerja dengan baik dengan menghasilkan uap buatan sehinga vivarium seperti berkabut dan lampu LED sebagai penerang.

\section{UCAPAN TERIMA KASIH}

Dalam merancang penelitian ini tentu ada berbagai pihak yang mendukung atas ketercapaian penelitian ini sebagai kesuksesan Tri dharma perguruan tinggi.

Penulis ingin mengucapkan terima kasih kepada :

1. LLDIKTI Wilayah X.

2. Universitas Putra Indonesia YPTK Padang.

3. LPPM Universitas Putra Indonesia YPTK Padang.

4. Fakultas Ilmu Komputer, Universitas Putra Indonesia YPTK Padang.

\section{DAFTAR PUSTAKA}

[1] Dahlan, B. Bin. (2017). Sistem Kontrol Penerangan Menggunakan Arduino Uno Pada Universitas Ichsan Gorontalo. ILKOM Jurnal Ilmiah, 9(3), 282. https://doi.org/10.33096/ilkom.v9i3 .158.282-289

[2] Dewi, K., \& Kifaya, I. (2016). Perancangan Pengabut Rumah Walet Otomatis. November.

[3] Ihsanto, E., \& Hidayat, S. (2014). Rancang Bangun Sistem Pengukuran Ph Meter Dengan Menggunakan Mikrokontroller Arduino UNO. Teknologi Elektro, 5(3), 139-146.

[4] Iskandar, A., Muhajirin, M., \& Lisah, L. (2017). Sistem Keamanan Pintu Berbasis Arduino Mega. Jurnal Informatika Upgris, 3(2), 99-104. https://doi.org/10.26877/jiu.v3i2.18 03

[5] Maulana, L., \& Yendri, D. (2018). Rancang Bangun Alat Ukur Tinggi dan Berat Badan Ideal Berdasarkan Metode Brocha Berbasis Mikrokontroler. Journal of Information Technology and Computer Engineering, 2(02), 76-84. https://doi.org/10.25077/jitce.2.02. 76-84.2018

[6] Padma Diana, I. P. A., Putu Raka Agung, I. G. A., \& Rahardjo, P. (2018). Perancangan Modul Pembelajaran Huruf Braille Berbasis Mikrokontroler Untuk Membantu Proses Belajar Disabilitas Netra. Jurnal SPEKTRUM, 5(1), 5. https://doi.org/10.24843/spektrum. 2018.v05.i01.p03

[7] Ratna, S., Informasi, F. T., Islam, U., Muhammad, K., Al, A., \& Banjarmasin, B. (2019). Abstrak Jurnal Ilmiah "Technologia" Tech nologia " Vol 10, No. 4, OktoberDesember 2019 Jurnal IImiah " Technologia ." 10(4), 179-185.

[8] Rumimper, R., Sompie, S. R. U. A., \& Mamahit, D. J. (2016). Rancang Bangun Alat Pengontrol Lampu Dengan Bluetooth Berbasis Android. E-Journal Teknik Elektro Dan Komputer, 5(3), 24-33.

[9] Utara, U. S., Utara, U. S., \& Utara, U. S. (2017). Rancangan Bangun Generator Kabut Air Memamfaatkan Membrane Ultrasonic Berbasis Mikrokontroller ATMEGA328.

[10]Zainuri, A., Wibawa, U., \& Maulana, E. (2015). Jurnal EECCIS. Implementasi Bluetooth $\mathrm{HC}-05$ Untuk Memperbarui Informasi Pada Perangkat Running Text Berbasis 
Jurnal KomtekInfo, Vol.7 No.4 Tahun 2020

e-ISSN : 2502-8758 || p-ISSN : 2356-0010

DOI : $\underline{10.35134 / \text { komtekinfo.v7i4 }}$

Page : 260-269

Android, 9(2), 163-167. 